\title{
Endocytosis of Non-Enveloped DNA Viruses
}

\author{
Maude Boisvert and Peter Tijssen \\ Additional information is available at the end of the chapter \\ http://dx.doi.org/10.5772/45821
}

\section{Introduction}

Endocytosis is critical for the internalization and maturation of many DNA viruses. Since all non-enveloped DNA viruses replicate in the nucleus, they can also take advantage of endocytosis trafficking for transport from the cell surface to the nucleus. The internalization often involves clathrin-mediated endocytosis (ClaME), but also macropinycytosis, caveolae-mediated endocytosis (CavME) and other less characterized internalization mechanisms. Viruses strive to avoid evidence of cell entry, and thus of immune attack, and therefore as much as possible take advantage of existing systems. Consequently, virus entry has been extensively studied to understand endocytosis. In contrast to inert cargo, like dextran, well-defined virus particles can be mutated to change biological properties, e.g. receptor interaction, maturation steps or penetration of the endosomal membrane to the cytosol, and thus provide additional tools for the study of endocytosis. However, the use of viruses also poses major challenges since (i) the virus particle population may be heterogeneous; (ii), only one out of a thousand particles may be infectious; (iii), viruses may be using different pathways at the same time; (iv), viral entry pathways may depend on the cell types used; (v), some viruses, eg. papillomaviruses are difficult to reproduce in tissue culture; (vi) the mobility of the infecting particles may be heterogeneous; and (vii), viruses often developed mechanisms to avoid infected cells (e.g. viral neuraminidases). The use of purified viruses and cell cultures, although imparting useful models, may not reproduce the in vivo situation. Moreover, viruses may have adapted to in vitro cells and may use other pathways then in vivo. In this chapter, we focus on entry of non-enveloped DNA viruses, such as circoviruses, parvoviruses, polyomaviruses, papillomaviruses, adenoviruses and iridoviruses. Particularly, we will highlight the effects of binding of these viruses to the cell surface, the internalization and endocytosis processes, and escape from endosomes by breaching the endosomal barrier. The wide array of strategies employed by these viruses, even within the same virus family, will be highlighted. An understanding of these processes, which may result in a plethora of ef- 
fects on cells, is essential for a wide variety of applications in basic research as well as providing blueprints for applied usages such as gene therapy.

\section{Overview of non-enveloped DNA viruses and tools to study their entry}

\subsection{Non-enveloped DNA viruses}

Viruses can be used as a tool to study endocytosis since their defined structure can be modified specifically by site-directed mutagenesis to study different parts of the endocytic pathways. Functions related to virus entry are embedded in the virus capsid. Therefore, we will summarize here the structures and properties of these viruses. All, except the iridoviruses, have been solved by X-ray crystallography and their properties are recapitulated in Table 1.

\subsubsection{Circoviruses}

Circoviruses are among the smallest DNA viruses; the diameter of the icosahedral particle is about $20 \mathrm{~nm}$. The virus has a circular, $2 \mathrm{~kb}$ single-stranded DNA genome (ssDNA). The T=1 capsid consists of 60 subunits $(1,2)$. The best-known species infect pigs and birds. Soluble monomers of the porcine circovirus 2 (PCV2) capsid have been expressed in E.coli and could be assembled into virus-like particles (VLPs). X-ray crystallography (2) revealed two protrusions emanating from the icosahedral 2- and 5-axes. PEPSCAN analysis (3) and structural analysis (2) identified 4 surface epitopes, two epitopes at the subunit interface near the 3fold axis and two at the interior surface. The interior epitope mapped to the $\mathrm{N}$-terminus of the subunit, which, as for parvoviruses and some other animal viruses, may be transiently externalized. This domain may have membrane-disrupting activity required for infectivity. PCV2 binds to heparan sulfate receptors on cells (4). Clefts that bind sulfate ions, and are positively charged at neutral $\mathrm{pH}$, on the exterior surface of the PCV2 structure surrounding the 2-fold axis are highly conserved. Heparan sulfate may thus bind to this region.

\subsubsection{Parvoviruses}

The icosahedral viral capsid of parvoviruses infecting vertebrates is made up of two or three proteins that have large common C-terminals part and different $\mathrm{N}$-terminal extensions, due to different translation initiations or proteolysis. The rugged capsid structure is very resistant to acids, bases, solvents such as chloroform or butanol, and temperatures to beyond 50 $\mathrm{C}$. The X-ray structures of many parvoviruses have been solved, but these structures lack the $\mathrm{N}$-terminal extensions (5-10). Parvoviruses, such as the minute virus of mice (MVM), package their linear ssDNA genome into preformed capsids, in a process that is probably driven by a virus-encoded NS1 (helicase). Each of the twelve 5-fold vertices have a roughly cylindrically shaped pore created by the juxtaposition of 10 antiparallel beta-strands, two from each of the 5-fold-related capsid proteins. Mutant capsids that have their 5-fold channels blocked are unable to package DNA, strongly suggesting that the 5-fold pore is the packaging portal for genome entry (11). It may also be the DNA delivery site after the conforma- 
tional changes occurring in these pores in the endosome. Virtually all parvoviruses also contain a phospholipase A2 activity (PLA2) in the N-terminal extension of the largest capsid protein $(12,13)$. This domain is located inside the capsid and needs to be externalized for it to be able to breach the endosomal membrane barrier (12). These multistep conformational changes occur in the endosomes.

\begin{tabular}{|c|c|c|c|c|}
\hline Family & Structure $^{2}$ & Capsid composition & Entry mode & Escape \\
\hline Circ & PDB : 3ROR & $\begin{array}{c}\mathrm{T}=1 \\
60 \text { proteins/subunits } \\
20 \mathrm{~nm}\end{array}$ & ClaME & $\begin{array}{l}\text { Uncoating by } \\
\text { serine } \\
\text { proteases; } \\
\text { Escape early } \\
\text { (not at very low } \\
\text { pH) }\end{array}$ \\
\hline Par & PDB : 2CA & $\begin{array}{c}\mathrm{T}=1 \\
60 \text { proteins/subunits } \\
25 \mathrm{~nm}\end{array}$ & $\begin{array}{c}\text { Majority: ClaME } \\
\text { Also: CavME } \\
\text { Macropino- } \\
\text { cytosis } \\
\text { CLIC/GEEC }\end{array}$ & $\begin{array}{l}\text { LE / lysosomes } \\
\text { Viral PLA2 } \\
\text { activity }\end{array}$ \\
\hline Polyc & PDB : 1SVA & $\begin{array}{c}\mathrm{T}=7 \\
360 \text { VP1 proteins } \\
\text { (72 capsomers) } \\
45 \mathrm{~nm}\end{array}$ & CavME & $\begin{array}{l}\text { ER, Viral VP2 } \\
\text { cellular } \\
\text { proteins BAP31 } \\
\text { and BiP }\end{array}$ \\
\hline Papi & PDB : 1LOT & $\begin{array}{c}\mathrm{T}=7 \\
360 \mathrm{~L} 1 \text { proteins } \\
\text { (72 capsomers) } \\
55 \mathrm{~nm}\end{array}$ & $\begin{array}{c}\text { Majority: } \\
\text { ClaME } \\
\text { Other: } \\
\text { CavMEMacropi } \\
\text { no- } \\
\text { cytosis }\end{array}$ & $\begin{array}{l}\text { Cellular } \\
\text { Nexin-17 } \\
\text { viral capsid } \\
\text { protein L2 }\end{array}$ \\
\hline Adenoviridae $^{1}$ & PDB : 1VSZ & $\begin{array}{c}\text { Pseudo- } \mathrm{T}=25 \\
720 \text { hexon proteins } \\
\text { ( } 240 \text { subunits) } \\
12 \text { penton bases } \\
\text { Cement proteins } \\
\text { Fiber proteins } \\
90 \mathrm{~nm}\end{array}$ & $\begin{array}{c}\text { Majority: } \\
\text { ClaME } \\
\text { Others: } \\
\text { Macropino- } \\
\text { cytosis }\end{array}$ & $\begin{array}{l}\text { Sorting } \\
\text { endosomes } \\
\text { Penton base, } \\
\text { L3/p23 } \\
\text { protease, } \\
\text { protein VI. }\end{array}$ \\
\hline
\end{tabular}




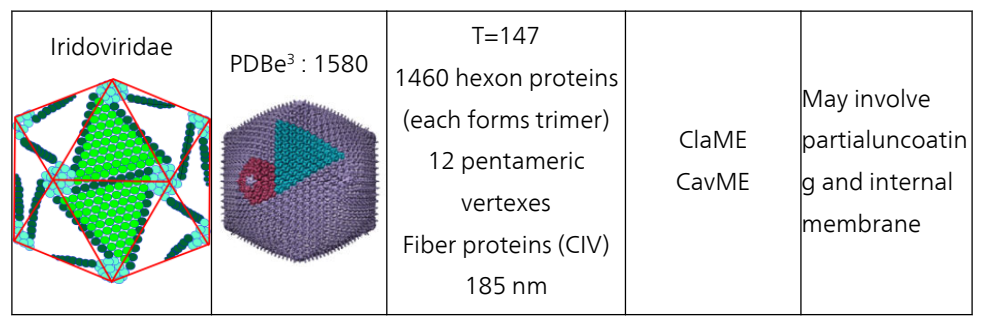

Table 1. Synopsis of nonenveloped DNA viruses and entry and exit of endosomes

\subsubsection{Polyomaviruses}

The $45 \mathrm{~nm}$ diameter $\mathrm{T}=7$ icosahedral particles polyomaviruses virions (SV40, BK virus) are non-enveloped. The crystal structure of SV40 has been solved and found to be organized unlike other viruses (14-16). The 3 capsid proteins, VP1-3, form 72 pentameric capsomers, 60 hexagonally coordinated plus 12 pentamerically coordinated (at the vertices), i.e. the capsomers at the 5 -fold axis have all 5 neighboring capsomers whereas the other 60 have 6 capsomer neighbors via different intercapsomer interactions. The 72 pentameric capsomers in each virus particle contain together 360 copies of VP1 plus 30-60 copies each of VP2 and VP3, i.e. $~ 1$ copy in the tapering cavity inside of each pentamer. VP2 is important during cell entry. Each copy of VP1 has a sialic acid binding site on the surface and these are part of the receptor-binding site for the virus; hence the particles have haemagglutinating properties. The long C-terminal arms of VP1 stabilize the interpentameric contacts by invading neighboring capsomers. VP2 is myristylated at its NH2-terminus, and is also believed to be important in holding the particle together (17). Recently, it was also shown that the cysteine at position 9 in VP1 forms C9-C9 disulfide bonds and thus contributes to intercapsomeric crosslinks (18).

\subsubsection{Papillomaviruses}

Previously, the Papovaviridae family contained both the Papillomaviridae and the Polyomaviridae. Now, these two are separate families but their earlier co-classification indicates a certain degree of similarity $(19,20)$. The diameter of the papillomaviruses is about $20 \%$ larger than that of polyomaviruses, mainly due to the larger L1 as compared to VP1 $(21,22)$.The atomic structure resembles that of polyomaviruses (23), in particular the core capsomers, and the $55 \mathrm{~nm}$ diameter $\mathrm{T}=7$ icosahedral particles also have 72 pentameric capsomers $(20,24$, 25). However, the cysteine residues involved in intercapsomer disulfide bonds are C175 and C428 (23).

\subsubsection{Adenoviruses}

The over 50 serotypes of the Adenoviridae family can be categorized in about 6 subgroups. The icosahedral outer capsid of these viruses surrounds a (double stranded) dsDNA-protein core and has a diameter of about $90 \mathrm{~nm}$ (26). The most prevalent protein in the capsid are 720 subunits of hexon proteins arranged in 240 trimers ( 12 hexon trimers on each of the 20 
facets); penton base proteins are found at each of the 12 vertices. A unique "spike" or trimeric fiber is associated to each of these penton bases. Moreover, the penton base contains an exposed arginine-glycine-aspartate (RGD) motif and both this motif and the fiber are involved in cell attachment. Minor capsid proteins (III, VI, VIII and IX) are also present to stabilize the capsid. The pseudo- $\mathrm{T}=25$ capsid is the largest virus so far of which the near-atomic structure has been solved by X-ray crystallography $(27,28)$. The fibers were shortened in order to make crystallization possible. An unusual symmetry mismatch occurs between the fivefold symmetric penton base and the threefold symmetric fiber protein. This has a potential impact on cell receptor interactions and subsequent disassembly in the endosomal pathway. In this respect, the ability of the penton base to adapt large changes, resulting in very different central pore sizes, is striking. The large-pore, but not the small-pore, conformation would allow insertion of the fiber. These conformational changes seem to reflect early events in cell entry when the fiber is released from the penton base.

\subsubsection{Iridoviruses}

Iridoviruses have recently been reviewed in detail (29). Currently, the Iriodviridae family is divided into five genera: Iridovirus, Chloriridovirus, Ranavirus, Lymphocystivirus, and Megalocytivirus. Chilo Iridescent Virus (CIV) is the type specie of this family. Although, it is unlikely that the structures of these large icosahedral dsDNA viruses are amenable to X-ray crystallographic analysis, various details about their assembly and structure have been obtained by cryo-electron microscopy (cryo-EM) and 3D reconstruction $(30,31)$. Enveloped particles that acquire an envelope by budding from the plasma membrane seem also to exist for all iridoviruses and may be more infectious than naked particles (29). The CIV T=147 capsid has a diameter of about $185 \mathrm{~nm}$. Its dsDNA-protein core is surrounded by a lipid bilayer, derived from the endoplasmic reticulum that follows the contour of the outer icosahedral capsid shells. The external capsid is essentially consistent with the classical quasiequivalent symmetry prediction. It has 1460 hexameric capsomers and 12 pentameric vertex complexes that are organized in 20 trisymmetrons and 12 pentasymmetrons. Each capsomer in CIV, but not in frog virus type 3 (FV3), has a central fiber that appears to be extended about $35 \mathrm{~nm}$ beyond the capsid surface. These flexible fibers are probably the first component that comes into contact with the host cell. The minor zip and finger proteins are suggested to stabilize the capsid by acting as intercapsomer cross-links and could be important during virus conformational changes during entry. Furthermore, the minor anchor protein appears to extend into the internal lipid membrane for further stabilization. Although the inner membrane is generally $4 \mathrm{~nm}$ thick, it is only $3 \mathrm{~nm}$ in regions just below the pentameric complex. Small icosahedral viruses are usually assembled from monomers having hexamers and pentamers, or only pentamers, in quasi-equivalent environments. The larger viruses, like adenovirus, iridoviruses and large algal and bacterial viruses, have significantly greater coding capacities that have allowed divergent evolution and specialized pentameric complexes. In contrast to adenovirus, CIV does not have fibers associated with its pentameric complexes but a complex mushroom-like structure that has the appearance of a fiveblade propeller. This propeller could have an important role in assembly but a role in entry is not excluded. 


\subsection{Tools used to study endocytosis and trafficking of viruses}

\subsubsection{Imaging}

Transmission electron microscopy (TEM) is still widely used, and enables visualization of virus in endocytic cups (size and shape, presence of coats). For instance, TEM imaging demonstrated that Adeno-associated virus 5 (AAV5) can enter cells in non-coated vesicles, pointing to a non-clathrin mechanism (32). Immunohistochemistry using gold-labeled antibody can be used in TEM to colocalize structures. Scanning electron microscopy (SEM) facilitates 3D imaging that can be helpful to see ruffles on cell surface, as shown in an AAV2 study (33).

Fluorescence, particularly confocal microscopy, is an excellent tool to visualize viruses and cellular structures. It is frequently used to confirm use of a pathway by co-localisation of the virus and pathway components. It can also be used in live imaging to see the movements of the virus along cellular structures, such as plasma membrane (filopodia) and actin or tubulin structural networks. One should be aware that conformational epitopes may change during the endosomal pathway and that some viruses have very high GCE/FFU ratios (genome copy equivalent/foci forming unit), so that an excess of non-infectious virus in the viral preparation could mask the real infectious pathway. For further details, see chapter by Aaron and Timlin.

\subsubsection{Chemical inhibitors}

Chemical inhibitors are widely used and provide an excellent basis for endocytosis studies of a particular cargo (34) (Table 2). These are usually not expensive, easy to work with, and have the major advantage of providing a uniform treatment of the cells. None of the extensively used pharmacological inhibitors have complete specificity, but, some parameters can be controlled to limit the possibility of artefacts. Dose-response curves to establish lowest concentrations and shortest exposition times possible to limit side effects on the cells are valuable, and limit upregulation of compensatory mechanisms. It is also easy to wash out the inhibitors to recover a normal state of the cells, in the case of reversible inhibition. This also remove virus that did not yet penetrate the cells, and allows continuing the infection with only endocytosed virus in normal conditions of the cells. Confirmation with another inhibitor, without the same side effects, is convenient. A combination of methods with siRNA or dominant negative/constitutive mutants can be exploited to identify the entry pathway of a specific cargo. Readers are referred to selected literature for further details on any particular inhibitor for comprehensive discussions $(34,35)$.

\subsubsection{Dominant-negative/constitutive mutants}

Dominant-negative mutants drive the expression of non-functional versions of the protein of interest (Table 3). The regular protein is still present but strong expression of the mutant form will result in an inactive pathway (35). The main challenges using dominant-negative mutants is to choose the appropriate protein and to achieve high efficiencies in the transfec- 
tion of the constructs. Stable transfection, with selection of the transfected cells, is not a good choice, since long (constitutive) treatments that donwnregulate a pathway is prone to result in the upregulation of compensatory pathways that could be used by the cargo. Using dominant-negative mutants can also be more time-consuming and become more costly than chemical inhibitors. A constitutively active protein can block a pathway at a certain step, e.g. constitutively active Rab5 protein inhibits the passage from early endosomes and late endosomes (see section 4.2.2.). There is also a complex signalisation process involved in endocytosis, and any modification can have some side effect on the cells.

\begin{tabular}{|c|c|c|c|}
\hline Pathway & Inhibitor & Mechanism of action & Side effect \\
\hline \multirow[t]{4}{*}{ Clathrin } & $\begin{array}{l}\text { Hypertonic } \\
\text { sucrose }\end{array}$ & $\begin{array}{l}\text { Dispersion of clathrin } \\
\text { sub-units, preventing } \\
\text { basket formation }\end{array}$ & $\begin{array}{l}\text { Inhibits CavME and } \\
\text { macropinocytosis (high } \\
\text { doses);Induces important } \\
\text { remodelling of the actin } \\
\text { network }\end{array}$ \\
\hline & Chlorpromazine & $\begin{array}{l}\text { Clathrin and AP2 } \\
\text { relocalized at the } \\
\text { endosomes }\end{array}$ & $\begin{array}{l}\text { Inhibits phagocytosis and } \\
\text { formation of large vesicles }\end{array}$ \\
\hline & $\begin{array}{l}\text { Potassium } \\
\text { depletion }\end{array}$ & $\begin{array}{l}\text { Prevents clathrin } \\
\text { basket formation }\end{array}$ & $\begin{array}{l}\text { Reduces other non-clathrin } \\
\text { endocytosis mechanisms; } \\
\text { Alteration of actin cytoskeleton }\end{array}$ \\
\hline & $\begin{array}{l}\text { Cytosol } \\
\text { acidification }\end{array}$ & $\begin{array}{l}\text { Blocks budding of } \\
\text { vesicles }\end{array}$ & $\begin{array}{l}\text { Inhibition of macropinocytosis; } \\
\text { Alters actin cytoskeleton }\end{array}$ \\
\hline \multirow[t]{3}{*}{ Caveolae } & Nystatin & $\begin{array}{l}\text { Induces cholesterol } \\
\text { sequestration and } \\
\text { aggregation }\end{array}$ & $\begin{array}{l}\text { Can affect macropinocytosis at } \\
\text { high concentrations }\end{array}$ \\
\hline & $\begin{array}{l}\text { Methyl- } \beta- \\
\text { cyclodextrin }\end{array}$ & $\begin{array}{l}\text { Disperse cholesterol, } \\
\text { mislocalisation of } \\
\text { caveolin-1 }\end{array}$ & $\begin{array}{l}\text { High concentration leads to } \\
\text { inhibition of ClaME and fluid } \\
\text { phase endocysotis; } \\
\text { Affects actin structure }\end{array}$ \\
\hline & $\begin{array}{l}\text { Cholesterol } \\
\text { oxydase }\end{array}$ & $\begin{array}{l}\text { Relocalization of the } \\
\text { caveolin-1 to the } \\
\text { Golgi }\end{array}$ & $\begin{array}{l}\text { Action of the enzyme is } \\
\text { sensitive to several factors that } \\
\text { may lead to false negatives }\end{array}$ \\
\hline \multirow[t]{2}{*}{$\begin{array}{l}\text { Macropino- } \\
\text { cytosis }\end{array}$} & Amiloride & $\begin{array}{l}\text { Inhibits } \mathrm{Na}^{+} / \mathrm{H}^{+}- \\
\text {ATPase exchangers; } \\
\text { Prevents membrane } \\
\text { extension formation }\end{array}$ & $\begin{array}{l}\text { Can affect ClaME; } \\
\text { Can reduce lipid raft } \\
\text { internalization; } \\
\text { Alters actin structure }\end{array}$ \\
\hline & Cytochalasin D & $\begin{array}{l}\text { Prevents membrane } \\
\text { projection by actin }\end{array}$ & $\begin{array}{l}\text { Other mechanisms depend on } \\
\text { actin and membrane modelling }\end{array}$ \\
\hline
\end{tabular}




\begin{tabular}{|l|l|l|l|}
\hline & Wortmannin & $\begin{array}{l}\text { Inhibition of PI3K, } \\
\text { important for } \\
\text { formation and fusion } \\
\text { of vesicles }\end{array}$ & $\begin{array}{l}\text { Not exclusive for } \\
\text { macropinocytosis }\end{array}$ \\
\hline $\begin{array}{l}\text { Acidification of } \\
\text { endosomes }\end{array}$ & $\begin{array}{l}\text { Bafilomycin A } \\
\text { Beak base } \\
\text { Block the V-ATPase } \\
\text { proton pumps }\end{array}$ & $\begin{array}{l}\text { No effect on recycling pathway, } \\
\text { prevents transfer from EE to LE }\end{array}$ \\
\hline chloroquine $)$ & $\begin{array}{l}\text { Gently raise the pH of } \\
\text { the compartment; }\end{array}$ & $\begin{array}{l}\text { Does not affect the transport of } \\
\text { cargo to the lysosomes }\end{array}$ \\
\hline
\end{tabular}

Table 2. Chemical inhibitors to study endocytosis of viruses

\begin{tabular}{|c|c|c|}
\hline $\begin{array}{l}\text { Pathway / } \\
\text { component }\end{array}$ & Protein & Mode of action \\
\hline \multirow[t]{2}{*}{ ClaME } & EPS15 & $\begin{array}{l}\text { Deletion of EH domains results in loss of recruitment of } \\
\text { clathrin and AP2 at endocytosis site (36) }\end{array}$ \\
\hline & Clathrin & $\begin{array}{l}\text { Overexpression of the HUB domain in the cells leads to the } \\
\text { inhibition of the cage assembly at endocytosis site. }\end{array}$ \\
\hline \multirow[t]{2}{*}{ CavME } & Caveolin-1 & $\begin{array}{l}\text { Overexpression of the WT protein stabilizes the caveolin } \\
\text { structure located at the plasma membrane, thus prevent } \\
\text { membrane curvature and/or vesicle budding }\end{array}$ \\
\hline & Caveolin-3 & $\begin{array}{l}\text { Deletion of N-terminal, or fusion with EGFP in N-terminal } \\
\text { inhibits endocytosis (37) }\end{array}$ \\
\hline Dynamin & $\begin{array}{l}\text { Dynamin-1/ } \\
\text { Dynamin-2 }\end{array}$ & $\begin{array}{l}\text { K44A is widely used. Dynamin is involved in ClaME, CavME } \\
\text { and other less described non-ClaME/ non-CavME } \\
\text { mechanisms }\end{array}$ \\
\hline \multirow[t]{2}{*}{$\begin{array}{l}\text { Macropino- } \\
\text { cytosis }\end{array}$} & Pak-1 & Important in the regulation of vesicle cycling \\
\hline & Rac-1 & $\begin{array}{l}\text { Important for membrane ruffling, inhibited with } \\
\text { N17Rac1(33); Blocks cell cycle in G2/M phase }\end{array}$ \\
\hline $\begin{array}{l}\text { Other } \\
\text { pathways }\end{array}$ & GRAF1 & $\begin{array}{l}\text { Key player in the newly described CLIC/GEEC pathway (33, } \\
\text { 38) }\end{array}$ \\
\hline
\end{tabular}

Table 3. Dominant-negative / constitutive mutants

\subsubsection{Gene silencing}

Another way to target a particular protein, as opposed to chemical inhibitors and dominantnegative mutants, is gene silencing. Several endocytosis studies use transfection of small interfering RNA (siRNA) or small hairpin RNA (shRNA) to specifically knock down key proteins of different endocytosis pathways (see section 4.3). This method is relatively simple 
and selective, but depends on good delivery of the interfering RNA. A good knockdown of the target protein needs to be confirmed by Western blot analysis, and only then can endocytosis studies can be performed. However, since there are some entry pathways not fully described yet, it remains a possibility that some proteins that we believe specific to a certain entry mode will be demonstrated in the future to be involved with other pathways.

\section{Docking of virus to cell surface and induced signalling pathways}

\subsection{Virus attachment to cells}

The first interaction between a virus and a cell is crucial to promote endocytosis. In its simplest form, the virus binds to a cell surface receptor and triggers directly its endocytosis. However, several viruses have either multiple receptors, or they also bind abundant structure on the cell surface, e.g. as sialic acids, before binding to the "real" receptor. In its most sophisticated form, the virus needs to bind to a primary receptor to trigger conformational changes that will allow binding to a secondary receptor that will in turn trigger endocytosis. Binding to the cell surface is also the first element that can determine viral tropism, if the virus uses a specific receptor present only on certain cell type.

\subsubsection{Cell attachment by circoviruses}

Monocyte/macrophage lineage cells are target cells PCV2 replication. Misinzo et al. (4) used the porcine monocytic cell line 3D4/31, that supports PCV2 replication in vitro, and glycosaminoglycans (GAG), used by several viruses as receptors, for attachment studies. They observed that heparin, heparan sulfate (HS), chondroitin sulfate B (CS-B), but not CS-A, and keratan sulfate reduced PCV2 infection when these GAG were incubated with PCV2 prior to and during inoculation of 3D4/31 cells. Also, enzymatic removal of HS and CS-B prior to PCV2 inoculation of 3D4/31 cells significantly reduced PCV2 infection. Similarly, when PCV2 virus-like particles (VLP) were allowed to bind onto 3D4/31 cells in the presence of heparin and CS-B, attachment was strongly reduced. This was confirmed for the wild-type virus. Together, these results demonstrated that HS and CS-B are components of the attachment receptors for PCV2.

\subsubsection{Cell attachment by parvoviruses}

The Parvoviridae family is very large, and its members infect a wide range of hosts from invertebrates to vertebrates such as humans. Family members display different strategies to complete their replication cycle. Most parvovirus interactions with cells are neuraminidasesensitive, indicating binding to abundant sialoglycoproteins, e.g. porcine parvovirus (PPV) (39), dependoviruses (AAVs) (40), minute virus of mice (MVM), canine (CPV) and feline (FPV) parvoviruses (41). These glycan-specific interactions occur usually in the depressions around the twofold symmetry axes. Specific receptors are not currently known for all parvoviruses. One of the best characterized interactions is between CPV/FPV and the transferrin 
receptor (TfR) (42). CPV and FPV is a well-documented evolution of virus characterised by species jump. Thus FPV, a virus that can infect only cats, acquired two mutations on the capsid protein, enabling the binding to the canine TfR and thus emerge as CPV2, a virus that could only infect dogs, and that caused serious health problems in dogs in the late 1970's. Shortly after, the CPV2a emerged and this virus was able to infect both species, because it could bind to both receptors. PPV, that can bind and enter many cell types, but that can complete the replication cycle only in few cell types (43).

\subsubsection{Cell attachment by polyomaviruses}

SV40 binds cell surfaces via major histocompatibility complex 1 (MHC-1) (37). This binding provokes the clustering of the virus in lipid rafts, and entry by CavME. Infection can be efficiently inhibited by pre-incubation of the cells with antibodies directed at the MHC-1. It was observed that initial binding (when endocytosis is inhibited by incubating the cells at $4 \mathrm{C}$ ) occurs outside of the lipid raft, and that at that point, there was no co-localisation with caveolin (37). However, when the cells are at $37 \mathrm{C}$, translocation to the caveolin-positive domain is fast and efficient.

\subsubsection{Cell attachment by papillomaviruses}

Uptake of papillomaviruses is very slow, and the virus can stay at the cell surface for several hours and the half-time of uptake can be as high as 14 hours. A major issue with this family of viruses that have slowed progress in their research was that, in the host, viruses only complete their replication cycle in terminally differentiated keratinocytes (44). Thus, it was only since the 2000's that virus could be efficiently produced, using "packaging cell lines" $(45,46)$. It is also hard to infect cells in vitro, since there are only a few permissive cell lines such as the HaCaT cells. There is still limited information concerning the uptake and nuclear delivery of those viruses. Concerning binding, growing evidence suggests that the extracellular matrix (ECM) can provide the first binding of the virus. Capsid protein L1 binds to the heparan sulfate proteoglycans (HSPG), or laminin 5 present in the ECM. Then the virus is transferred to the cellular filopodia, and slowly translocated to the body of the cell. Binding to this primary receptor will trigger conformational changes, lowering affinity for the primary receptor, and allowing binding to a still unidentified secondary receptor. The minor L2 capsid protein, usually not accessible at the virus surface will become exposed, and cleaved by cellular furin. This cleavage is absolutely required for successful infection and it is believed to be important later in the endosomal escape. Although in vitro binding to the surface receptor is critical, the in vivo situation is different in that the basement membrane is the primary site of binding (47).

\subsubsection{Cell attachment by adenovirus}

The first high-affinity interaction between the cell and the virus occurs between the globular knob of the C-terminal segment of the viral fiber protein and the cellular CAR (Coxackie and Adenovirus Receptor, belonging to the Ig superfamily) or CD46, for sub group C and B adenovirus respectively. The second interaction, of low affinity is between the RGD motive 
on the viral penton base and the cellular integrins. Together they will form a strong and irreversible connection between the cell and the virus, leading to endocytosis (48).

\subsubsection{Cell attachment by iridovirus}

Little is known about iridovirus receptors; although the central fibers of the capsomers have been proposed to be involved (31) not all iridoviruses have these fibers. Eaton et al. showed that anti-FV3 serum present at the time of FV3 (Ranavirus) infection enhances infectivity of the virus in non-immune teleost cell lines, but not in a non-immune mammalian cell line, suggesting a cell surface receptor specific to teleost cell lines (49). They observed that this antibody dependent enhancement (ADE) of FV3 was dependent on the Fc portion of antiFV3 antibodies but not to complement.

\subsection{Induced signalling pathways}

Signalization from cell surface is an important process in coordination of different events of an organism. Readers are referred to two extensive reviews on the subject for further details $(50,51)$. Signalling also regulate endocytosis processes. Binding to a receptor can trigger signalling pathways that promote endocytosis by upregulating the quantity of clathrin at the cell surface. Src kinase was shown to increase new clathrin basket formation by phosphorylation of the clathrin, leading to assembly of the triskelions (52). Activation of p38 increases Rab5 recruitment to plasma membrane, promoting endocytosis (53). Raf kinase is implicated in recycling of the transferrin receptor to the cell surface (54). In the case of viruses, binding of the virus to the cell surface receptor can trigger other endocytosis mechanisms such as macropinocytosis which is not a constitutive process (55). Differential endocytosis can also be used by the cell to control the level of signalling. For example, activated EGFR can be endocytosed by ClaME or CavME. CavME is used when the level of activation is particularly high and lead to degradation of the receptor, while ClaME leads to recycling of the receptor.

\section{Entry mechamisms}

\subsection{Initial steps of entry}

Viruses have developed multiple ways to hijack cellular entry processes ideally without any remaining trace at the cell surface to prevent detection by the immune system. The three best understood mechanisms are clathrin-mediated endocytosis (ClaME), caveolae endocytosis (CavME) and macropinocytosis (Figure 1). 


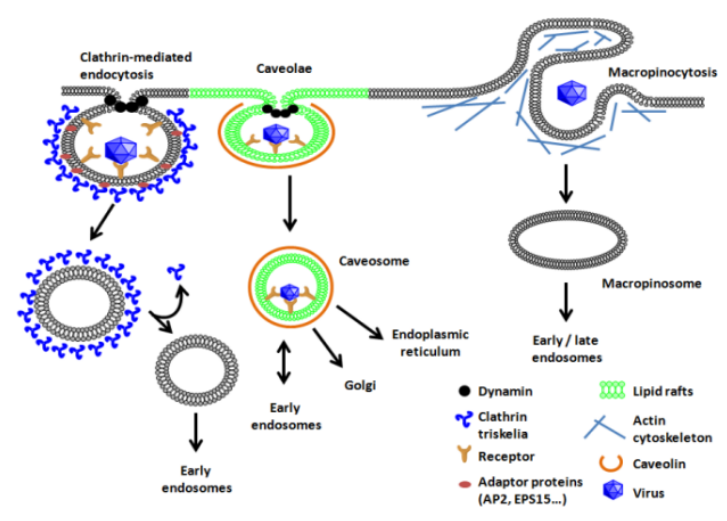

Figure 1. Major endocytosis pathways. Major components of 3 most described endocytosis mechanisms. Main intracellular targets are indicated (e.g. early endosome for most, but also others such as endoplasmic reticulum and Golgi for the CavME

ClaME is probably the best characterized cellular uptake mechanism. Cellular uptake was first observed using transmission electron microscopy (TEM) in the 1960's. One main characteristic is the assembly of clathrin proteins forming basket shape vesicles. As a result it was postulated that the size of material that can be taken via ClaME is limited in order to form the basket clathrin cage. ClaME proceeds in five steps (56). First, it requires specific receptor engagement to trigger intracellular signaling required for the beginning of membrane modeling, a process called "nucleation". The key element is the highly conserved adaptor protein AP2, recruited from the cytoplasm to the membrane. The next step is the "cargo selection". At this stage there will be several interactions between the cargo, its receptor and several adaptor and accessory proteins. The tetrameric AP2 adaptor protein, like clathrin, has disproportionally large numbers of interactors, such as dynamin and Eps15, and is a hub of protein networks. Accessory proteins may swap from the AP2 appendage hub to the clathrin hub during coated pit assembly. Clathrin protein will also be recruited at the membrane in the "clathrin coat assembly" step. Clathrin proteins are recruited as triskelions and will be polymerized into the basket shape forming pentagons and hexagons. When the polymerization reaches the point where only a neck shape remains between the forming coated vesicle and the plasma membrane the dynamin protein will be recruited to perform the "vesicle scission" step required for the budding. GTP hydrolysis will be necessary to complete the process. The final step will be the "uncoating and recycling" step. This uncoating is important before the nascent vesicle can move on and fuse with the endosomes. After this, there will be a sorting step deciding whether the vesicle is simply returned to the plasma membrane or pushed forward into the endosomal pathway.

CavME main characteristic is its origin in lipid rafts, small domains rich in sphingolipids and cholesterol (57). This endocytosis mechanism thus depends on cholesterol homeostasis of the cell. Caveolin is a membrane protein that binds to the cholesterol, as a result depletion 
of cholesterol leads to mis-localization of caveolin and inhibition of the pathway. Several components are involved such as caveolin-1 (caveolin-2 can be present but not required, caveolin-3 is present primarily in muscles), dynamin and actin (implicated in caveolin rigidity/motility). Vesicles acquire caveolin coats while forming; the released caveosomes will keep a neutral $\mathrm{pH}$ and can interact with the endosomal pathway, the Golgi system, or as in the case of SV40 endocytosis, transit to the smooth endoplasmic reticulum (37).

Macropinocytosis is an active uptake pathway that requires activation in most cells types (58). Activation of the pathway will lead to intense actin and microfilaments modulation and membrane ruffling. By definition pinocytosis is the uptake of fluids and membranes by the cell ("fluid phase endocytosis"). The main difference with other endocytosis mechanisms is that, once activated, uptake of material will not depend on receptor binding. In macropinocytosis, the membrane ruffles will or will not be closed and the size of the macropinosome is not directed by the cargo. The diameter will usually range between 0.5 to $10 \mu \mathrm{m}$, and thus is larger than in other endocytosis mechanisms. In contrast to phagocytosis, that is limited to few cell types, most cells are capable of macropinocytosis. The closure of the macropinosomes will require several cellular factors. Myosins will provide contractile activity, and fusion factors together with kinases, GTPases, will help the process. Once in the cytoplasm, macropinosomes will acidify and interact with the endosomal pathway.

Phagocytosis is a pathway limited to specialised immune cells such as macrophages, dendritic cells, neutrophils and monocytes. This pathway is mostly used by bacteria and fungi. Recent studies reported the use of this pathway also by herpes simplex virus (59) and mimivirus (60), both displaying membranes. The non-enveloped DNA viruses that fall in the scope of this chapter do not use it.

Novel pathways were revealed by investigating entry mechanism of viruses. They are often referred to as clathrin independent endocytosis. Since molecular components involved in these mechanisms depend not only on cargo but also on cell type, several groups suggested classifying them as dependent or independent of such components. For example, no matter which mechanism is involved the forming vesicle will need to be pinched of the cellular membrane. While ClaME, uses dynamin proteins some clathrin-independent endocytosis, were reported to be dependent on dynamin and some are independent.

\subsection{Endosomal pathway}

Regardless of the endocytosis pathways, virtually all the vesicles formed during entry will fuse or at least interact with the early endosomes, and acquire the Rab5 and EEA1 markers (61). After endocytosis, cargos enter the highly-coordinated endosomal pathways (62). General endocytosis is a highly active and dynamic process. In a mammalian cell up to $180 \%$, of the cell surface will be endocytosed each hour (62). A simple model of the endosomal pathway is shown in Figure 2. 


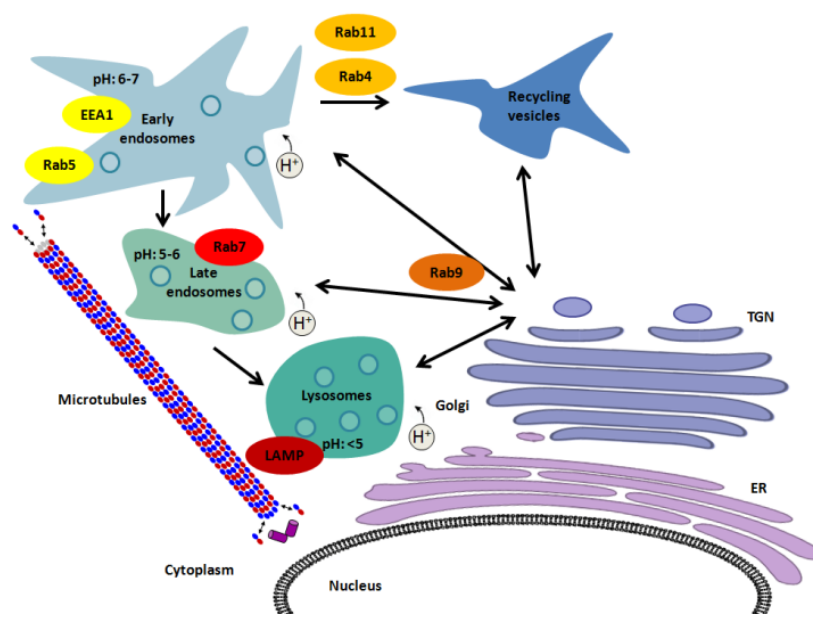

Figure 2. Endosomal pathway. Most endocytosis mechanisms lead to the early endosomes. Sorting will determine if the vesicle is recycled to the cell surface, caveosomes or continue in the degradation pathway towards the lysosomes. Acidification occurs throughout the endosomal pathway. Crosstalk between the trans-Golgi network (TGN) and the different compartments provides cellular components to the pathway. Transport of the vesicles on microtubules ensures steady traffic towards the nucleus. Rab proteins are regulators of the pathway and can be used as markers.

The first compartment encountered is the early endosome (EE) which is slightly acid ( $\mathrm{pH}$ 6.5), highly pleomorphic, large and tubular shaped. The EEs are the main organelle where sorting will take place. The main markers of EEs are Rab5 and EEA1 proteins. The tubular projection contains microdomains for sorting, and will generate vesicles targeted to the recycling endosomes (with Rab4 and Rab11), or the trans-Golgi network (TGN). The TGN is constantly communicating with the endosomes at all stages of the pathway. It provides components necessary for the maturation of the endosomes. A marker for the shuttles between the TGN and the endosomes is Rab9. All endosomes contain internal vesicles that are used to isolate certain components such as receptors. While endosomes proceeds to the end of the pathway, these internal vesicles increase greatly in numbers. It has become clear for polyomaviruses and papillomaviruses that EE shuttle also to caveosomes (section 5). Maturation of the EEs into late endosomes (LE) includes replacement of the Rab5 proteins by Rab7 proteins (63). The maturation of EE in LE will create intermediate endosomes containing both Rab5 and Rab7 markers. The displacement of Rab5 by Rab7 begins by the recruitment of Rab7 by the activated form of Rab5. This recruitment will lead to the inactivation and dissociation of Rab5. This sequence is absolutely required for EE conversion into LE. The newly formed Rab7-positive endosomes will recruit specific proteins for the maturation of the LE.

LEs have an increased regular oval shape, their $\mathrm{pH}$ is more acidic $(\mathrm{pH}$ 5.5), and they contain many internal vesicles (62). LEs are generated close to the cell surface and will mature while moving towards the nuclear periphery. Fusion events will occur between LEs, and between $\mathrm{LE}$ and lysosomes. The lysosome is highly acid $(\mathrm{pH}<5)$ and contains various hydrolases. 
Acidification of the endosomes is provided by proton pumps within the membrane of the endosomes, the V-ATPases. The gradual acidification of the pathway is regulated by the concentration of these pumps, the isoforms present, and the presence of other complexes. Markers of the lysosomes are the LAMP proteins. In addition to transport of cargo to the lysosomes, there is also transport of cellular components to the lysosomes. The different hydrolases and membrane proteins are renewed to conserve the lysosome integrity, acidic $\mathrm{pH}$ and activities. Transport comes mostly from the TGN via the late endosomes. Mobility of the endosomes is dynamic, and involves both major transport on actin and the microtubule (Mt) networks. Also, transport is not unidirectional, but oscillating, since the vesicles interact both with the kinesins (transport toward cell periphery) and the dyneins (transport toward nucleus) on the Mts. As the maturation of the endosomes proceeds, the net movement will be toward the nucleus (64). Movement of the LEs toward the nucleus is important to reach the lysosomes (mostly located in the nuclear periphery). The actin network is also important for transport of the EEs to the LEs, and to generate small vesicles from the EEs that are targeted to the TGN or from LEs toward lysosomes. Actin is also important for fusion between the LEs and lysosomes.

There are more than 60 different Rab GTPases that have specific membrane localizations. Rab small GTPases are important regulators of the endosomal pathway (65) and thus they can be used as markers, or as inhibitors of specific parts of the pathway by expression of dominant-negative form. The regulation switch is the association of the Rab protein with either GDP or GTP, (66). Rab proteins are involved in multiple events. Rab5 is implicated in the recruitment of the clathrin subunits, with other regulator proteins, such as GAPGDI, will enable uncoating of the vesicle. Rab proteins were also shown to interact with actin (myosin) and microtubule (dynein and kinesin) motors. An example is the Rab11 family of proteins that link recycling vesicles to myosin (67). Also an effector of the Rab7 protein interacts with the dynein motor to promote minus-end traffic on the microtubules, transporting late ensosomes toward the lysosomes. Membrane fusion also involves several proteins, including the Rab protein, and SNAREs (soluble NSF attachment protein receptor) (68). In this case Rab protein could mediate targeting of the appropriate membrane and docking of the membranes, for SNAREs to achieve fusion event.

\subsection{Pathways selected by various non-enveloped DNA viruses}

Members of the same family or the same genus may use different pathways. There is growing evidence that certain viruses evolved the use of multiple entry pathways. This can be an advantage to infect different cell types. However, it can be difficult to determine whether multiple entry pathways are involved or if one complex pathway use different components. Often viruses can have multiple sequential binding to the cell surface, which can trigger different signaling pathways inside the cell, calling for components normally observed to drive different entry pathways. 


\subsubsection{Endocytosis of circoviruses}

Porcine circovirus (PCV) infects a wide variety of cell types, including hepatocytes, cardiomyocytes, and macrophages via an unknown receptor. PCV utilizes ClaME to enter the cell, though other pathways may be involved $(69,70)$. In contrast, although a dynamin- and cholesterol-independent, but actin- and small GTPase-dependent pathway, allows PCV2 internalization in epithelial cells that leads to infection, a clathrin-mediated PCV2 internalization in epithelial cells is not followed by a full replication (69). Recent evidence suggests dendritic cells (DC) are involved through their particularly elevated endocytosis of the virus. PCV2 can accumulate to high levels both in vitro and in vivo, a phenomenon dependent on the virus capsid protein, inferring that the viral capsid or genome impedes DC endocytic degradation of the virus (71). However, PCV2 in DC does not interfere with processing of other antigens.

\subsubsection{Endocytosis of parvoviruses}

Most Parvoviridae family members were shown to enter cells by ClaME $(39,72,73)$. When investigating early steps of infection of porcine parvovirus (PPV), we found that inhibition of ClaME affected PPV infection, but we could not achieve complete inhibition (39). Inhibition of fluid phase endocytosis components also reduced PPV infection. Interestingly combination of inhibition of both pathways reduced more the infection level, but still, some cells could be infected, suggesting a third pathway might be involved. It is important to consider the fact that inhibition of endocytosis pathways will result in upregulation of compensatory mechanisms that can influence viral infection. Laboratory experiments often use highly-purified viruses. We demonstrated, however, that after replication most PPV is present in aggregates which used preferentially fluid phase endocytosis, compared to the purified isolated particles that preferred ClaME (39). Purified viral preparations might not reflect the actual mode of infection inside the host. In vivo, aggregates are likely to form and be involved in further infection of other cells.

Adeno-associated viruses (AAVs) are members of the Dependovirus genus. They cannot complete their replication cycle without a helper virus, such as adenovirus. Many groups study AAVs entry and genome delivery in the nucleus, since they represent a good platform for gene therapy. However, the early steps of infection are not efficient (just like all parvoviruses) and a better understanding of the mechanism involved could lead to genetically modified viruses that are better suited for gene delivery. AAV5 can enter cells via ClaME (32), but it was shown to be able to use CavME too (32). To date, it is the only known parvovirus using this pathway. The authors observed the virus in non-coated vesicles using TEM. These vesicles contained caveolin-1. This pathway could not be found in all cell types, highlighting the fact that specific cargos can use different pathways depending on the cell type.

CLIC-GEEC (CLathrin-Independent Carrier/GPI-anchored protein-Enriched Endosomal Compartment) is a clathrin/caveolin independent entry pathway, identified in the past 10 years Figure 3. This pathway is constitutive, and thus attractive for pathogens. The size and shape of the vesicles can vary greatly, and could potentially accommodate large or multiple viruses. An important protein is GRAF1, serving as a marker or by inhibiting the pathway 
by gene silencing. Another interesting feature of the pathway, for viruses, is that resulting vesicles will acidify, and can provide proper environment for conformational changes.

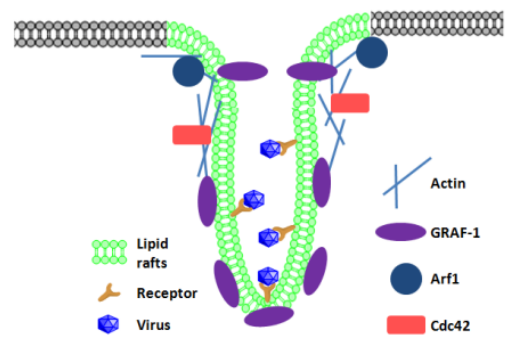

Figure 3. CLIC-GEEC entry mechanism. Characteristic features of this endocytosis mechanism include location in the lipid rafts, tubular shaped, large, pleomorphic invaginations, taking up large volume of membrane and fluids. Those required actin polymerisation involving Cdc42, and membrane curvature involving Arf1. GRAF-1 is a key player that can be used as marker or as target to inhibit this mechanism of uptake.

Adeno-associated viruses type 2 (AAV2) endocytosis was recently extensively studied, and revealed a complex mechanism (33). This endocytosis was independent of clathrin and caveolin. Also, only one known inhibitor (EIPA) of macropinocytosis could affect the entry of the virus. This inhibitor was shown to inhibit Rac1 and Cdc42 signaling, thus affecting other mechanisms as well (74). This endocytosis required actin cytoskeleton and cholesterol. Membrane and actin remodeling was observed by TEM and immunofluorescence, respectively. Virus bound to the cell surface was located in lipid rafts. These features led to the recently described CLIC/GEEC pathway (38). Dominant negative mutants revealed the critical role of Arf1 and Cdc42 for AAV2 endocytosis (33). GRAF1 (GTPase Regulator Associated with Focal adhesion kinase) was also demonstrated to be essential in CLIC-GEEC endocytosis, and postulated to act as a "coat" for that pathway (38). Expression of a truncated mutant of the protein, as well as the use of siRNA, both reduced the endocytosis of AAV2 (33). GRAF-1 is not implicated in ClaME or CavME, and thus appears specific to CLIC-GEEC endocytosis. Combination of GRAF1 and dynamin inhibition further diminished entry of AAV2, confirming that both proteins are important for endocytosis of AAV2. Interestingly, endosomes of the CLIC-GEEC pathway are known to acidify quickly and inhibition of acidification reduced transduction by AAVs (33). Then the virus is transported to the Golgi apparatus, and no co-localisation is observed with endosomal markers (Rab proteins).

\subsubsection{Endocytosis of polyomaviruses}

SV40 is probably the best described virus using CavME (75). Initial observations were made by electron microscopy (TEM) where the virus was not present in a coated vesicle, as opposed to ClaME. Entry is dependent of cholesterol, actin polymerization, dynamin and caveolin $(37,76)$. SV40 provides a good example of a particular traffic that does not involve classical endosomal pathway (37). Virus can be a great tool when used as a tracer for the 
endocytosis pathway, by using fluorescent viruses and either regular confocal microscopy or live imaging. Pelkmans et al. showed that SV40 traffic to the ER in two distinct steps (37). They saw, using live imaging that the virus once bound to its receptor will move on the surface of the cell until it reach the caveolae. Then the virus is endocytosed into very small vesicles. These will transport the virus to larger vesicle already present in the cytoplasm. These vesicle contained several virus particle and were caveolin-positive ("caveosomes"). Then the virus left the caveosomes in tubular-shaped small vesicles that moved along the microtubules toward the nucleus. The virus was then delivered to the smooth ER. No co-localisation with clathrin was observed, and inhibition of ClaME does not affect SV40 infection. SV40 was also reported to infect cells that do not express caveolin (77). In these cells, entry involved tyrosine kinases and cholesterol but again was not dependent of clathrin or dynamin (77). Entry could not be reduced when inhibiting ClaME or macropinocytosis. It was also faster than regular CavME, but led to the ER in a microtubule dependent manner similar to CavME. This is a good example of virus adaptation, enabling infection in a wide range of cells. In caveolae-expressing cells, both pathways are used. They share important characteristics such as dependence of cholesterol, tyrosine kinases and transit in neutral vesicles using the microtubule network leading to the ER (77).

BK virus is a polyomavirus that poses serious health problems (78). It causes diseases in immunosuppressed patients after renal transplants. Immunosuppression therapy can enable usually non-threatening viruses to replicate easily leading to diseases. More than $80 \%$ of the population has been infected often at young age and latent infection of the kidney is present in $50 \%$ of the population. Efforts are being made to understand infection by this virus. It was demonstrated that it hijacks CavME, as its relative virus SV40. Cholesterol depletion efficiently inhibited infection. Knock-down of caveolin-1 by siRNA inhibited the infection, while a knockout of clathrin had no effect. Immunofluorescence and co-localisation with confocal microscopy confirmed that BK virus use CavME in cell culture (78-80).

\subsubsection{Endocytosis of papillomaviruses}

Papillomaviruses are a good example of different family members using different entry pathways even after binding to similar receptors, thus co-receptors could shunt the virus to different pathways. BPV1 entered cells by ClaME (81), and HPV31 preferred CavME (82). To determine which pathway was important they used chemical inhibitors, dominant-negative mutants and TEM. Another publication showed that for HPV16 and HPV31 macropinocytosis was important in NK cells (83). In this case, membrane ruffling was observed when the cells were incubated with the virus-like particles (VLPs). Then, co-uptake of fluid phase was demonstrated with fluorescent dextran. Inhibition by chemical inhibitors prevented this fluid-phase uptake. In term of RhoGTPases, HPV VLPs induced activation of Cdc42 and inhibition of Rac1. Papillomaviruses are highly asynchronous and their pathways chosen are disputes in the literature. 


\subsubsection{Endocytosis of adenoviruses}

Adenovirus could be observed in clathrin-coated vesicles by TEM (84). It is also present in non-coated vesicles. Dominant-negative constructs confirmed the ClaME (55). The involvement of integrins $(85,86)$ suggests that adenovirus endocytosis is highly regulated. These integrins activate $\mathrm{PI}(3) \mathrm{K}$ which in turn induces actin polymerization and promotes adenovirus endocytosis (87). Another observation was that fluid uptake (macropinocytosis) increased with adenovirus infection (55). Amiloride was effective to inhibit infection. This additional infection pathway also required actin, small Rho GTPases and PKC.

\subsubsection{Endocytosis of iridoviruses}

The enveloped form of the iridovirus FV3 (genus Ranavirus) was discovered in early 1980s by TEM research, and shown to be internalized by ClaME whereas the naked particles were suggested to enter by fusion at the plasma membrane $(29,88)$. This model was questioned in recent reports with a closely related virus (TFV) and the ISKNV virus $(89,90)$ with both pointing to caveolae-dependent endocytosis. However, caution is warranted since infection of cells from non-physiological host, i.e. BHK-21, may cloud a direct comparison of TFV and FV3 entry. Similar studies coupled with TEM could resolve these issues. The TFV iridovirus, a ranavirus nearly identical to FV3, enters cells by an atypical, $\mathrm{pH}$-dependent, CavME pathway. Experiments using chlorpromazine and over-expression of a dominant-negative form of Esp15 that inhibited assembly of clathrin-coated pits did not affect entry into HepG2 cells. Also, endocytosis of TFV was dependent on membrane cholesterol and was blocked by caveolin-1 scaffolding domain protein. Therefore, Guo et al. suggested that FV3, since its nearly identical in nucleotide sequence to TFV, may also enter via CavME. Later, these authors demonstrated that ISKNV, a fish iridovirus, enters fish cells also via CavME since inhibitors of ClaME had no effect on infection, in contrast to inhibitors of caveolin-1-involved signaling events (90). Moreover, ISKNV co-locates with caveolin-1 during virus infection and is dependent on dynamin and the microtubule cytoskeleton.

\section{Virus maturation and endosomes escape}

Non-enveloped viruses display a variety of strategies to gain access to the cytoplasm of the cell. Conformational changes are required in capsids to expose hydrophobic domains that anchor or disrupt the endosomal membrane during breaching. Parvoviruses have acquired an enzyme for membrane translocation. Virus trafficking is therefore highly temporally and spatially regulated and a plethora of tools have been developed to study these events.

\subsection{Endosomal trafficking of circoviruses and escape to cytoplasm}

PCV2 enters monocytic cells predominantly by ClaME and requires an acidic environment for infection. After endosomal escape, the virus aggregates in intracytoplasmic inclusion bodies (ICIs). Subsequently, PCV2 closely associates with mitochondria, completing a first 
cytoplasmic phase and enters the nucleus for replication (91). In epithelial cells, PCV2 is internalized via a clathrin-, caveolae-, and dynamin-independent small GTPase-regulated pathway (69).The latter leads to a more efficient PCV2 replication while the former seems to trap PCV2 leading to accumulation of the virus within epithelial cells. Inhibition of acidification of the endosomal/lysosomal system reduces PCV2 infection of the monocytic cells, indicating the requirement for a $\mathrm{pH}$ drop during replication. Surprisingly, inhibiting acidification highly increases PCV2 replication in epithelial cells, indicating that uncoating occurs at another $\mathrm{pH}$. Serine proteases mediate PCV2 uncoating in both epithelial cells and cells of the monocytic cells but may have different optima in these cells (92). It is not clear how this uncoating process impacts on the endosomal escape.

\subsection{Endosomal trafficking of parvoviruses and escape to cytoplasm}

Parvoviruses have a unique enzyme domain, phospholipase A2, in their capsid $(12,13,93)$. This protein domain with this motif is located inside the mature virion, and thus the virus needs to undergo a conformational change in order to expose and use this enzyme. The pentamer at the fivefold symmetry axis has a $0.8 \mathrm{~nm}$ central pore and is itself encircled by a 1.5 nm-deep depression ("canyon"). The hairpins of the central cylinder (see section 2.1.2) can thus move outward leading to a greater pore and allowing N-termini of VP2, during the transit in the endosome and acidification (94), to become exposed one by one and their $\mathrm{N}$ termini proteolytically cleaved, yielding successively a larger pore. The internal unique part of VP1 (that resists proteolysis) is then able to externalize and expose its phospholipase A2 domain. Phospholipases catalyze hydrolysis of phospholipids, providing a means to breach the endosomal barrier. This motif is absolutely essential for parvoviruses infection and acts prior to the delivery of the genome to the nucleus (13). Millimolar calcium concentrations present in the endosome but not in the cytosol, are required for optimal activity of the enzyme (12). Since it was required after accumulation of the virus in the perinuclear region, but prior to DNA expression in the nucleus, it was hypothesized that its role could be the ensodomal escape. Co-uptake studies showed that small dextran particles, but not $\alpha$-sarcin, could be released from the endosomes together with parvovirus escape. These observations suggested that parvovirus escape implicated small pore formation and not broad endosome disruption. Viruses harboring mutations in the PLA2 enzymatic domain remained trapped in endosomes in perinuclear areas, but could be complemented in trans in co-infection experiments with wild-type capsids (93). Moreover, induced endosomes disruption induced by treatment of the cells with polyethylenimine (PEI) was enough to rescue the infection, strongly suggesting that the main function of PLA2 is the escape of the virus from the ensosomal pathway.

\subsection{Endosomal trafficking of polyomaviruses and escape to cytoplasm}

SV40 enters via caveolin-1 containing vesicles that budded from the caveolae and that are transferred to caveosomes (lack markers for endosomes, lysosomes, ER and Golgi) (37). SV40 is then transferred from caveolin-free, tubular vesicles to the ER via an intermediate COP1 compartment that is brefeldin A-sensitive (95). Interestingly, polyomavirus is deliv- 
ered to early endosomes and a crosstalk between ClaME and CavME has been reported for JCV (96). Nevertheless, after passage through early endosomes these are sorted to caveosomes. Escape occurs from the ER to the cytosol before reaching the nucleus (97). An elegant and elaborate study in an attempt to describe mechanisms involved in this escape was published in 2011 (97). TEM studies suggested profound conformational changes in the ER where the capsid diameter decreased from $45 \mathrm{~nm}$ to $34 \mathrm{~nm}$. These conformational changes led to exposing structural protein VP2, which was not accessible in the mature virion that entered the cell. This VP2 protein contains hydrophobic structures that interact with the ER membrane. In the absence of VP2, the capsid can be targeted to the ER, but would not be able to transit back to the cytosol. There are several cellular proteins essential for SV40 escape to the cytosol. BAP31, highly-abundant membrane protein of the ER, is essential for SV40 infection. The chaperone BiP is also important for the escape, and will play its role after BAP31-induced conformational changes in the capsid suggesting that the ERAD-factors (isomerases, Derlin) assist is in SV4 ER- cytosol dislocation as used for misfolded proteins (97).

\subsection{Endosomal trafficking of papillomaviruses and escape to cytoplasm}

This subject is, due to the lack of suitable study models, still controversial. Conformational changes occur quickly after HPV entry and capsid protein L1 conformational epitope becomes inaccessible after endocytosis (44). Uncoating can be observed by L2 detection (normally buried and inaccessible in mature virions), or DNA detection. Papillomavirus escape from the endosomal pathway, at a relatively early stage, and only partial co-localisation between the virus and the lysosome can be seen $(44,98)$. Structural protein L2 is a major player in the escape. The protein has a hydrophobic C-terminal, adjacent to positively-charged residues, believed to destabilize the membrane structure and leading to disruption. It was recently described that the cellular protein nexin-17 was also important (98). The suggested role of this protein is to retain the virus in the late endosomes, preventing degradation in the lysosomes. When this protein is knocked down, strong co-localisation of the virus with the lysosomes was observed. Importantly, the binding sequence in L2 protein is conserved among Papillomaviridae family, both for low- and high-risk viruses. Recent studies suggested that BPV1 and human papillomavirus type 16 (HPV16, the most common etiological agent of cervical cancer) enter via ClaME, but that subsequent steps, as for JCV polyomavirus, require caveolin-1-mediated trafficking $(81,99)$. This novel trafficking may explain the requirement for the CavME pathway because ClaME typically does not lead to the ER.

\subsection{Endosomal trafficking of adenoviruses and escape to cytoplasm}

During entry, fibers are released, the penton base structures dissociated, the proteins connecting the DNA to the inside surface of the capsid degraded or shed, and the capsid-stabilizing minor proteins eliminated (100). The uncoating process starts immediately upon endocytic uptake with the loss of fibers and ends with the uptake of dissociated hexon proteins and DNA into the nucleus. For the adenoviruses, the escape will occur quickly, and is postulated to be as early as the sorting endosomes (48). An acidic $\mathrm{pH}$ is not sufficient for 
conformational changes in the virus structure to occur but a large number of factors, such as integrin, are involved (101). Integrin binding together with CAR-mediated drifts supported fiber shedding from adenovirus particles, leading to exposure of the membrane-lytic internal virion protein VI and enhanced viral escape from endosomes (102). The Ts1 mutant, which lacks the viral protease and cannot process the capsid or release the fibers during endosomal trafficking, will not be able to breach the endosomal membrane and ends up in lysosomes where it is degraded (103).

For subgroup B adenoviruses, Kalin et al. showed by confocal laser scanning microscopy, electron microscopy, and live cell imaging (104) that Ad35 colocalized with fluid-phase markers in large endocytic structures that were positive for CD46, alphanu integrins, and also CtBP1 (89).Their results extended observations with HAdV-3 (Ad3), using chemical inhibitors and dominant-negative mutants, that macropinocytosis is an infectious pathway for subgroup B human adenoviruses in epithelial and hematopoietic cells.

\subsection{Endosomal trafficking of irdoviruses and escape to cytoplasm}

Maturation of iridoviruses during entry has not been investigated in detail. The minor zip and finger proteins may play an essential role for capsid destabilization. Uncoating may occur at the nuclear membrane but, unlike herpesviruses, iridovirus genomes are not infectious, indicating that virion-associated proteins are required to initiate viral gene transcription (105). Early EM studies showed that FV3 ended up in the lysosome (88); however this may be a non-productive pathway. It has been suggested that ISKNV traffics via the caveosome to the ER, similar to SV40, and TFV via the caveosome to the trans-Golgi (89, 90). Chitnis et al. demonstrated that apoptosis induction by CIV iridovirus : (i) requires entry and endocytosis of virions or virion proteins, (ii) is inhibited under conditions permitting early viral expression, and (iii) requires the JNK signaling pathway (106). Apoptosis was inhibited by Z-IETD-FMK, an apical caspase inhibitor, indicating that CIV-induced apoptosis requires caspase activity. The JNK inhibitor SP600125 demonstrated drastic suppression of CVPE-induced apoptosis and showed that the JNK signaling pathway is significant for apoptosis in this system. Virus interaction with the cell surface was not sufficient for apoptosis since $\mathrm{CIV}(\mathrm{UV})$ particles bound to polysterene beads failed to induce apoptosis. Furthermore, blocking viral DNA replication with aphidicolin or phosphonoacetic acid suppressed apoptosis and Cf-caspase-i activity, indicating that early viral expression is necessary for inhibition of apoptosis, and de novo synthesis of viral proteins is not required for induction.

\section{Conclusions}

Endocytosis is a wide subject that has been studied for a very long time. Viruses are definitely great tool to study endocytosis since they are masters in hijacking every single possibility of the cell to achieve infection. Elucidating steps in viral replication often leads to hitherto unknown mechanisms that expand our knowledge of normal cellular processes. It is also interesting to realise that significant differences are found inside a family of closely related vi- 
ruses. Co-evolution with different hosts, in different conditions pushed viruses to adapt in different direction and provide a great variety of tools. However, in the case of life threatening or economically-important viruses, it is sometimes very hard to find a way to prevent infection without impeding with normal cellular processes. This growing field of research will surely provide new exiting insights to previously unknown cellular process, and will continue to provide good targets for antiviral drugs.

\section{Acknowledgement}

Authors wish to thank Natural Sciences and Engineering Research Council of Canada for grant to support P.T. and for the scholarship to M.B.

\section{Author details}

Maude Boisvert and Peter Tijssen*

1 INRS-Institut Armand-Frappier, Institut Pasteur International Network, Université du Québec, QC,, Canada

\section{References}

[1] Crowther, ., Berriman, R. A., Curran, J. A., Allan, W. L., Todd, G. M., \& , D. Comparison of the structures of three circoviruses: chicken anemia virus, porcine circovirus type (2). and beak and feather disease virus. J Virol. 2003; . Epub 2003/12/04., 77(24), 13036-41.

[2] Khayat, ., Brunn, R., Speir, N., Hardham, J. A., Ankenbauer, J. M., Schneemann, R. G., et, A., \& al, . The (2). 3-angstrom structure of porcine circovirus 2. J Virol. 2011; . Epub 2011/06/03., 85(15), 7856-62.

[3] Mahe, ., Blanchard, D., Truong, P., Arnauld, C., Le Cann, C., Cariolet, P., et, R., \& al, . Differential recognition (2). ORF2 protein from type 1 and type 2 porcine circoviruses and identification of immunorelevant epitopes. J Gen Virol. 2000;81(Pt 7):1815-24. Epub 2000/06/22.

[4] Misinzo, ., Delputte, G., Meerts, P. L., Lefebvre, P., Nauwynck, D. J., Porcine, H. J., \& circovirus, . (2). uses heparan sulfate and chondroitin sulfate B glycosaminoglycans as receptors for its attachment to host cells. J Virol. 2006; . Epub 2006/03/16., 80(7), 3487-94. 
[5] Tsao, ., Chapman, J., Agbandje, M., Keller, W., Smith, K., Wu, H., et al. The three-dimensional structure of canine parvovirus and its functional implications. Science. (1991). Epub 1991/03/22., 251(5000), 1456-64.

[6] Kaufmann, ., El -Far, B., Plevka, M., Bowman, P., Li, V. D., Tijssen, Y., et, P., \& al, . Structure of Bombyx mori densovirus (1). a silkworm pathogen. J Virol. 2011; . Epub 2011/03/04., 85(10), 4691-7.

[7] Kaufmann, ., Bowman, B., Li, V. D., Szelei, Y., Waddell, J., Tijssen, P. J., et, P., \& al, . Structure of Penaeus stylirostris densovirus, a shrimp pathogen. J Virol. (2010). Epub 2010/08/13., 84(21), 11289-96.

[8] Simpson, ., Hebert, B., Sullivan, G. M., Parrish, C. R., Zadori, Z., Tijssen, P., et al. The structure of porcine parvovirus: comparison with related viruses. J Mol Biol. (2002). Epub 2002/02/06., 315(5), 1189-98.

[9] Simpson, ., Chipman, P. R., Baker, T. S., Tijssen, P., \& Rossmann, M. G. The structure of an insect parvovirus (Galleria mellonella densovirus) (37). 3.7 A resolution. Structure. 1998; . Epub 1998/11/18., 6(11), 1355-67.

[10] Agbandje Mc, ., Kenna, M., Llamas-Saiz, A. L., Wang, F., Tattersall, P., \& Rossmann, M. G. Functional implications of the structure of the murine parvovirus, minute virus of mice. Structure. (1998). Epub 1998/11/18., 6(11), 1369-81.

[11] Structure of a packaging-defective mutant of minute virus of mice indicates that the genome is packaged via a pore at a 5-fold axis. J Virol. 2011; . Epub 2011/03/04., 85(10), $4822-7$.

[12] Canaan, ., Zadori, S., Ghomashchi, Z., Bollinger, F., Sadilek, J., Moreau, M., et al. Interfacial enzymology of parvovirus phospholipases (2). J Biol Chem. 2004; . Epub 2004/01/17., 279(15), 14502-8.

[13] Zadori, ., Szelei, Z., Lacoste, J., Li, M. C., Gariepy, Y., Raymond, S., et, P., al, A., \& viral, phospholipase. (2). is required for parvovirus infectivity. Dev Cell. 2001; . Epub 2001/11/13., 1(2), 291-302.

[14] Yan, ., Stehle, Y., Liddington, T., Zhao, R. C., Harrison, H., \& , S. C. Structure determination of simian virus (40). and murine polyomavirus by a combination of 30 -fold and 5-fold electron-density averaging. Structure. 1996; . Epub 1996/02/15., 4(2), 157-64.

[15] Liddington, ., Yan, R. C., Moulai, Y., Sahli, J., Benjamin, R., Harrison, T. L., \& , S. C. Structure of simian virus (40). at 3.8-A resolution. Nature. 1991; . Epub 1991/11/28., 354(6351), 278-84.

[16] Baker, ., Drak, T. S., Bina, J., \& , M. The capsid of small papova viruses contains 72 pentameric capsomeres: direct evidence from cryo-electron-microscopy of simian virus 40. Biophys J. (1989). Epub 1989/02/01., 55(2), 243-53. 
[17] Streuli CH, Griffin BE. Myristic acid is coupled to a structural protein of polyoma virus and (40). Nature. 1987; . Epub 1987/04/09., 326(6113), 619-22.

[18] Schelhaas, ., Malmstrom, M., Pelkmans, J., Haugstetter, L., Ellgaard, J., Grunewald, L., et, K., al, Simian., Virus, ., depends, on. E. R., protein, folding., quality, control., factors, for., entry, into., \& host, cells. Cell. (2007). Epub 2007/11/06., 131(3), 516-29.

[19] Sapp, ., Day, M., Structure, P. M., attachment, , entry, of., polyoma, , \& papillomaviruses, . Virology. (2009). Epub 2009/01/23., 384(2), 400-9.

[20] Belnap DM, Olson NH, Cladel NM, Newcomb WW, Brown JC, Kreider JW, et al. Conserved features in papillomavirus and polyomavirus capsids. J Mol Biol. (1996). Epub 1996/06/07., 259(2), 249-63.

[21] Chen, ., Casini, X. S., Harrison, G., Garcea, S. C., \& , R. L. Papillomavirus capsid protein expression in Escherichia coli: purification and assembly (11). HPV11 and HPV16 L1. J Mol Biol. 2001; . Epub 2001/03/13., 307(1), 173-82.

[22] Chen, ., Garcea, X. S., Goldberg, R. L., Casini, I., Harrison, G., \& , S. C. Structure of small virus-like particles assembled from (1). L1 protein of human papillomavirus 16. Mol Cell. 2000; . Epub 2000/07/06., 5(3), 557-67.

[23] Modis, ., Trus, Y., Harrison, B. L., \& , S. C. Atomic model of the papillomavirus capsid. EMBO J. (2002). Epub 2002/09/18., 21(18), 4754-62.

[24] Hagensee ME, Olson NH, Baker TS, Galloway DA. Three-dimensional structure of vaccinia virus-produced human papillomavirus type 1 capsids. J Virol. (1994). Epub 1994/07/01., 68(7), 4503-5.

[25] Baker, ., Newcomb, T. S., Olson, W. W., Cowsert, N. H., Olson, L. M., Brown, C., \& , J. C. Structures of bovine and human papillomaviruses. Analysis by cryoelectron microscopy and three-dimensional image reconstruction. Biophys J. (1991). Epub 1991/12/01., 60(6), 1445-56.

[26] Chailertvanitkul VA, Pouton CW. Adenovirus: a blueprint for non-viral gene delivery. Curr Op Biotech. (2010). Epub 2010/07/20., 21(5), 627-32.

[27] Reddy VS, N(35). chiar SK, Stewart PL, Nemerow GR. Crystal structure of human adenovirus at 3.5 A resolution. Science. 2010; . Epub 2010/08/28., 329(5995), 1071-5.

[28] Reddy, ., Natchiar, S. K., Gritton, L., Mullen, T. M., Stewart, P. L., \& Nemerow, G. R. Crystallization and preliminary $\mathrm{X}$-ray diffraction analysis of human adenovirus. Virology. (2010). Epub 2010/04/17., 402(1), 209-14.

[29] Chinchar VG, Yu KH, Jancovich JK. The molecular biology of frog virus (3). and other iridoviruses infecting cold-blooded vertebrates. Viruses. 2011; . Epub 2011/11/10., 3(10), 1959-85.

[30] Yan, ., Olson, X., Van Etten, N. H., Bergoin, J. L., Rossmann, M., Baker, M. G., \& , T. S. Structure and assembly of large lipid-containing dsDNA viruses. Nature Struct Biol. (2000). Epub 2000/02/03., 7(2), 101-3. 
[31] Yan, ., Yu, X., Zhang, Z., Battisti, P., Holdaway, A. J., Chipman, H. A., et, P. R., \& al, . The capsid proteins of a large, icosahedral dsDNA virus. J Mol Biol. (2009). Epub 2008/11/26., 385(4), 1287-99.

[32] Bantel-Schaal, ., Braspenning-Wesch, U., Kartenbeck, I., \& , J. Adeno-associated virus type 5 exploits two different entry pathways in human embryo fibroblasts. J Gen Virol. (2009). 2):317-22. Epub 2009/01/15.

[33] Nonnenmacher, ., Weber, M., Adeno-associated, T., virus, ., infection, requires., endocytosis, through., the, C. L. I. C. G. E. E. C., \& pathway, . Cell Host Microbe. (2011). Epub 2011/12/20., 10(6), 563-76.

[34] Ivanov AI. Pharmacological inhibition of endocytic pathways: is it specific enough to be useful? Methods Mol Biol. (2008). Epub 2008/03/29., 440, 15-33.

[35] Sieczkarski SB, Whittaker GR. Dissecting virus entry via endocytosis. J Gen Virol. (2002). 7):1535-45. Epub 2002/06/21.

[36] Inhibition of clathrin-coated pit assembly by an Eps15 mutant. J Cell Sci. 1999;112 ( Pt 9):1303-11. Epub 1999/04/09.

[37] Pelkmans, ., Kartenbeck, L., Helenius, J., \& , A. Caveolar endocytosis of simian virus 40 reveals a new two-step vesicular-transport pathway to the ER. Nat Cell Biol. (2001). Epub 2001/05/02., 3(5), 473-83.

[38] Lundmark, ., Doherty, R., Howes, G. J., Cortese, M. T., Vallis, K., Parton, Y., et, R. G., $\&$ al, . The GTPase-activating protein (1). regulates the CLIC/GEEC endocytic pathway. Curr Biol. 2008; . Epub 2008/11/28., 18(22), 1802-8.

[39] Boisvert, ., Fernandes, M., Tijssen, S., \& , P. Multiple pathways involved in porcine parvovirus cellular entry and trafficking toward the nucleus. J Virol. (2010). Epub 2010/05/21., 84(15), 7782-92.

[40] Opie, ., Warrington, S. R., Jr , K. H., Agbandje Mc, Kenna. M., Zolotukhin, S., \& Muzyczka, N. Identification of amino acid residues in the capsid proteins of adeno-associated virus type (2). that contribute to heparan sulfate proteoglycan binding. J Virol. 2003; . Epub 2003/05/28., 77(12), 6995-7006.

[41] Hueffer, ., Govindasamy, K., Agbandje Mc, L., Kenna, M., \& Parrish, C. R. Combinations of two capsid regions controlling canine host range determine canine transferrin receptor binding by canine and feline parvoviruses. J Virol. (2003). Epub 2003/08/28., 77(18), 10099-105.

[42] Parker, ., Murphy, J. S., Wang, W. J., O’Brien, D., Parrish, S. J., \& , C. R. Canine and feline parvoviruses can use human or feline transferrin receptors to bind, enter, and infect cells. J Virol. (2001). Epub 2001/03/27., 75(8), 3896-902.

[43] Oraveerakul, ., Choi, K., Molitor, C. S., \& , T. W. Restriction of porcine parvovirus replication in nonpermissive cells. J Virol. (1992). Epub 1992/02/01., 66(2), 715-22. 
[44] Sapp, ., Bienkowska-Haba, M., Viral, M., entry, mechanisms., human, papillomavirus., long, a., journey, from., extracellular, matrix., to, the., \& nucleus, F. E. B. FEBS J. (2009). Epub 2009/11/03., 276(24), 7206-16.

[45] Buck CB, Pastrana DV, Lowy DR, Schiller JT. Efficient intracellular assembly of papillomaviral vectors. J Virol. (2004). Epub 2003/12/25., 78(2), 751-7.

[46] Pyeon, ., Lambert, D., Ahlquist, P. F., \& , P. Production of infectious human papillomavirus independently of viral replication and epithelial cell differentiation. Proc Natl Acad Sci U S A. (2005). Epub 2005/06/17., 102(26), 9311-6.

[47] Roberts, ., Buck, J. N., Thompson, C. B., Kines, C. D., Bernardo, R., Choyke, M., et, P. L., \& al, . Genital transmission of HPV in a mouse model is potentiated by nonoxynol-9 and inhibited by carrageenan. Nature Med. (2007). Epub 2007/07/03., 13(7), 857-61.

[48] Leopold PL, Crystal RG. Intracellular trafficking of adenovirus: many means to many ends. Adv Drug Del Rev. (2007). Epub 2007/08/21., 59(8), 810-21.

[49] Eaton, ., Penny, H. E., Brunetti, E., \& , C. R. Antibody dependent enhancement of frog virus 3 infection. Virol J. (2010). Epub 2010/02/20.

[50] Polo, ., Di Fiore, S., \& , P. P. Endocytosis conducts the cell signaling orchestra. Cell. (2006). Epub 2006/03/15., 124(5), 897-900.

[51] Sorkin, ., von, A., Zastrow, M., Endocytosis, , signalling, intertwining., \& molecular, networks. Nat Rev Mol Cell Biol. (2009). Epub 2009/08/22., 10(9), 609-22.

[52] Wilde, ., Beattie, A., Lem, E. C., Riethof, L., Liu, D. A., Mobley, S. H., et, W. C., al, E. G. F., receptor, signaling., stimulates, S. R. C., kinase, phosphorylation., of, clathrin., influencing, clathrin., redistribution, , \& uptake, E. G. F. Cell. (1999). Epub 1999/03/25., 96(5), 677-87.

[53] Cavalli, ., Vilbois, V., Corti, F., Marcote, M., Tamura, K., Karin, M., et al., The, stressinduced. M. A. P., kinase, p., regulates, endocytic., trafficking, via., \& the, G. D. I. (5). complex. Mol Cell. 2001; . Epub 2001/03/10., 7(2), 421-32.

[54] ase functions in ARF6 regulated endocytic membrane traffic. PloS one. 2009;4(2):e4647. Epub 2009/02/28.

[55] Meier, ., Boucke, O., Hammer, K., Keller, S. V., Stidwill, S., Hemmi, R. P., et, S., \& al, . Adenovirus triggers macropinocytosis and endosomal leakage together with its clathrin-mediated uptake. J Cell Biol. (2002). Epub 2002/09/11., 158(6), 1119-31.

[56] Mc Mahon, ., Boucrot, H. T., \& , E. Molecular mechanism and physiological functions of clathrin-mediated endocytosis. Nat Rev Mol Cell Biol. . Epub 2011/07/23., 12(8), 517-33.

[57] Lajoie, ., Nabi, P., \& , I. R. Regulation of raft-dependent endocytosis. J Cell Mol Med. (2007). Epub 2007/09/01., 11(4), 644-53. 
[58] Mercer, ., Helenius, J., \& , A. Virus entry by macropinocytosis. Nat Cell Biol. (2009). Epub 2009/05/01., 11(5), 510-20.

[59] Clement, ., Tiwari, C., Scanlan, V., Valyi-Nagy, P. M., Yue, T., Shukla, B. Y., novel, D. A., role, for., phagocytosis-like, uptake., in, herpes., simplex, virus., \& entry, . J Cell Biol. (2006). Epub 2006/09/27., 174(7), 1009-21.

[60] Ghigo, ., Kartenbeck, E., Lien, J., Pelkmans, P., Capo, L., Mege, C., et, J. L., \& al, . Ameobal pathogen mimivirus infects macrophages through phagocytosis. PLoS Pathog. (2008). Epub 2008/06/14.

[61] Mayor, ., Pagano, S., \& , R. E. Pathways of clathrin-independent endocytosis. Nat Rev Mol Cell Biol. (2007). Epub 2007/07/05., 8(8), 603-12.

[62] Huotari, ., Helenius, J., Endosome, A., \& maturation, E. M. B. O. J. (2011). Epub 2011/09/01., 30(17), 3481-500.

[63] Rink, ., Ghigo, J., Kalaidzidis, E., Zerial, Y., \& , M. Rab conversion as a mechanism of progression from early to late endosomes. Cell. (2005). Epub 2005/09/07., 122(5), 735-49.

[64] Driskell, ., Mironov, O. J., Allan, A., Woodman, V. J., \& , P. G. Dynein is required for receptor sorting and the morphogenesis of early endosomes. Nat Cell Biol. (2007). Epub 2006/12/19., 9(1), 113-20.

[65] Stenmark, ., \& , H. Rab GTPases as coordinators of vesicle traffic. Nat Rev Mol Cell Biol. (2009). Epub 2009/07/16., 10(8), 513-25.

[66] Pfeffer SR. Structural clues to Rab GTPase functional diversity. J Biol Chem. (2005). Epub 2005/03/05., 280(16), 15485-8.

[67] Seabra, ., Coudrier, M. C., \& , E. Rab GTPases and myosin motors in organelle motility. Traffic. (2004). Epub 2004/05/01., 5(6), 393-9.

[68] Stenmark, ., Parton, H., Steele-Mortimer, R. G., Lutcke, O., Gruenberg, A., Zerial, J., \& Inhibition, M. (5). rab5 GTPase activity stimulates membrane fusion in endocytosis. EMBO J. 1994; . Epub 1994/03/15., 13(6), 1287-96.

[69] Misinzo, ., Delputte, G., Lefebvre, P. L., Nauwynck, D. J., Porcine, H. J., circovirus, ., infection, of., epithelial, cells., is, clathrin., caveolae, , dynamin-independent, actin., Rho-G, T., Pase-mediated, , enhanced, by., \& cholesterol, depletion. Virus Res. (2009). Epub 2008/10/28., 139(1), 1-9.

[70] Misinzo, ., Meerts, G., Bublot, P., Mast, M., Weingartl, J., Nauwynck, H. M., \& , H. J. Binding and entry characteristics of porcine circovirus (2). in cells of the porcine monocytic line 3D4/31. J Gen Virol. 2005;86(Pt 7):2057-68. Epub 2005/06/17.

[71] Mc Cullough, ., Ruggli, K. C., Summerfield, N., \& , A. Dendritic cells--at the frontline of pathogen attack. Vet Immun Immunopathol. (2009). Epub 2008/11/28. 
[72] Douar, ., Poulard, A. M., Stockholm, K., Danos, D., \& , O. Intracellular trafficking of adeno-associated virus vectors: routing to the late endosomal compartment and proteasome degradation. J Virol. (2001). Epub 2001/02/13., 75(4), 1824-33.

[73] Parker JS, Parrish CR. Cellular uptake and infection by canine parvovirus involves rapid dynamin-regulated clathrin-mediated endocytosis, followed by slower intracellular trafficking. J Virol. (2000). Epub 2000/01/22., 74(4), 1919-30.

[74] Koivusalo, ., Welch, M., Hayashi, C., Scott, H., Kim, C. C., Alexander, M., et, T., \& al, . Amiloride inhibits macropinocytosis by lowering submembranous $\mathrm{pH}$ and preventing (1). and Cdc42 signaling. J Cell Biol. . Epub 2010/02/17., 188(4), 547-63.

[75] Norkin, ., Simian, L. C., virus, ., infection, via. M. H. C., class, I., molecules, , caveolae, Immunol., \& Rev, . (1999). Epub 1999/07/10., 168, 13-22.

[76] Pelkmans, ., Puntener, L., Helenius, D., \& , A. Local actin polymerization and dynamin recruitment in SV40-induced internalization of caveolae. Science. (2002). Epub 2002/04/20., 296(5567), 535-9.

[77] Damm, ., Pelkmans, E. M., Kartenbeck, L., Mezzacasa, J., Kurzchalia, A., Helenius, T., Clathrin, A., caveolin-1-independent, endocytosis., entry, of., \& simian, virus. (40). into cells devoid of caveolae. J Cell Biol. 2005; . Epub 2005/01/26., 168(3), 477-88.

[78] Moriyama, ., Marquez, T., Wakatsuki, J. P., Sorokin, T., \& , A. Caveolar endocytosis is critical for BK virus infection of human renal proximal tubular epithelial cells. J Virol. (2007). Epub 2007/06/08., 81(16), 8552-62.

[79] Dugan, ., Eash, S., Atwood, W. J., Update, on. B. K., virus, entry., \& intracellular, trafficking. Transplant Infect Dis. (2006). Epub 2006/06/01., 8(2), 62-7.

[80] Moriyama, ., Sorokin, T., Repression, A., of, B. K., virus, infection., of, human., renal, proximal., tubular, epithelial., cells, by., \& pravastatin, . Transplantation. (2008). Epub 2008/05/14., 85(9), 1311-7.

[81] Laniosz, ., Holthusen, V., Meneses, K. A., \& , P. I. Bovine papillomavirus type (1). from clathrin to caveolin. J Virol. 2008; . Epub 2008/04/18., 82(13), 6288-98.

[82] Bousarghin, ., Touze, L., Sizaret, A., Coursaget, P. Y., \& , P. Human papillomavirus types (1631). 31, and 58 use different endocytosis pathways to enter cells. J Virol. 2003; . Epub 2003/03/01., 77(6), 3846-50.

[83] Renoux, ., Bisig, V. M., Langers, B., Dortu, I., Clemenceau, E., Thiry, B., et, M., \& al, . Human papillomavirus entry into NK cells requires (16). expression and triggers cytotoxic activity and cytokine secretion. Eur J Immunol. 2011; . Epub 2011/08/11., 41(11), 3240-52.

[84] Brown DT, Burlingham BT. Penetration of host cell membranes by adenovirus (2). J Virol. 1973; . Epub 1973/08/01., 12(2), 386-96. 
[85] Suomalainen, ., Nakano, M., Boucke, M. Y., Keller, K., Greber, S., Adenovirus-activated, U. F., , P. K. A., p3, , \& , M. A. P. (38). pathways boost microtubule-mediated nuclear targeting of virus. EMBO J. 2001;20(6):1310-9. Epub 2001/03/17., 38.

[86] Wickham, ., Mathias, T. J., Cheresh, P., Nemerow, D. A., \& , G. R. Integrins alpha v beta (3). and alpha $\mathrm{v}$ beta 5 promote adenovirus internalization but not virus attachment. Cell. 1993; . Epub 1993/04/23., 73(2), 309-19.

[87] Li, ., Stupack, E., Klemke, D., Cheresh, R., Nemerow, D. A., \& , G. R. Adenovirus endocytosis via alpha(v) integrins requires phosphoinositide-3-OH kinase. J Virol. (1998). Epub 1998/03/14., 72(3), 2055-61.

[88] Braunwald, ., Nonnenmacher, J., Tripier-Darcy, H., \& , F. Ultrastructural and biochemical study of frog virus (3). uptake by BHK-21 cells. J Gen Virol. 1985;66 ( Pt 2): 283-93. Epub 1985/02/01.

[89] Guo, ., Liu, C. J., Wu, D., Yang, Y. Y., Yang, X. B., Mi, L. S., et, S., \& al, . Entry of tiger frog virus (an Iridovirus) into (2). cells via a $\mathrm{pH}$-dependent, atypical, caveola-mediated endocytosis pathway. J Virol. 2011; . Epub 2011/05/06., 85(13), 6416-26.

[90] Guo, ., Wu, C. J., Yang, Y. Y., Yang, L. S., He, X. B., Mi, J., et, S., \& al, . Infectious spleen and kidney necrosis virus (a fish iridovirus) enters Mandarin fish fry cells via caveola-dependent endocytosis. J Virol. (2012). Epub 2011/12/16., 86(5), 2621-31.

[91] Rodriguez-Carino, ., Duffy, C., Sanchez-Chardi, C., Mc Neilly, A., Allan, F., Segales, G. M., \& , J. Porcine circovirus type 2 morphogenesis in a clone derived from (35). 135 lymphoblastoid cell line. J Comp Pathol. 2011;144(2-3):91-102. Epub 2010/08/31.

[92] Nauwynck, ., Sanchez, H. J., Meerts, R., Lefebvre, P., Saha, D. J., Huang, D., et, L., \& al, . Cell tropism and entry of porcine circovirus (2). Virus Res. 2012;164(1-2):43-5. Epub 2011/11/22.

[93] Farr, ., Zhang, G. A., Tattersall, L. G., \& , P. Parvoviral virions deploy a capsid-tethered lipolytic enzyme to breach the endosomal membrane during cell entry. Proc Natl Acad Sci U S A. (2005). Epub 2005/11/15., 102(47), 17148-53.

[94] Mani, ., Baltzer, B., Valle, C., Almendral, N., Kempf, J. M., Ros, C., \& , C. Low pHdependent endosomal processing of (1). incoming parvovirus minute virus of mice virion leads to externalization of the VP1 N-terminal sequence (N-VP1), N-VP2 cleavage, and uncoating of the full-length genome. J Virol. 2006; . Epub 2005/12/28., 80(2), 1015-24.

[95] Norkin, ., Anderson, L. C., Wolfrom, H. A., Oppenheim, S. A., \& , A. Caveolar endocytosis of simian virus (40). is followed by brefeldin A-sensitive transport to the endoplasmic reticulum, where the virus disassembles. J Virol. 2002; . Epub 2002/04/23., 76(10), 5156-66.

[96] Querbes, ., O'Hara, W., Williams, G., \& Atwood, W. J. Invasion of host cells by JC virus identifies a novel role for caveolae in endosomal sorting of noncaveolar ligands. J Virol. (2006). Epub 2006/09/16., 80(19), 9402-13. 
[97] Geiger, ., Andritschke, R., Friebe, D., Herzog, S., Luisoni, F., Heger, S., et, T., \& al, B. A. (31). and BiP are essential for dislocation of SV40 from the endoplasmic reticulum to the cytosol. Nat Cell Biol. 2011; . Epub 2011/09/29., 13(11), 1305-14.

[98] Bergant, ., Marusic, M., Ozbun, Campos. S. K., Myers, M. P., Banks, L., Human, papillomavirus. L., facilitates, viral., escape, from., late, endosomes., via, sorting., \& nexin, 1. Traffic. (2012). Epub 2011/12/14., 13(3), 455-67.

[99] Laniosz, ., Dabydeen, V., Havens, S. A., \& Meneses, P. I. Human papillomavirus type 16 infection of human keratinocytes requires clathrin and caveolin-1 and is brefeldin a sensitive. J Virol. (2009). Epub 2009/06/06., 83(16), 8221-32.

[100] Greber, ., Willetts, U. F., Webster, M., Helenius, P., \& , A. Stepwise dismantling of adenovirus (2). during entry into cells. Cell. 1993; . Epub 1993/11/05., 75(3), 477-86.

[101] Meier, ., Greber, O., Adenovirus, U. F., endocytosis, J., \& Gene, . (2004). Suppl 1:S . Epub 2004/02/24., 152-63.

[102] Burckhardt, ., Suomalainen, C. J., Schoenenberger, M., Boucke, P., Hemmi, K., Greber, S., \& , U. F. Drifting motions of the adenovirus receptor CAR and immobile integrins initiate virus uncoating and membrane lytic protein exposure. Cell Host Microbe. (2011). Epub 2011/08/17., 10(2), 105-17.

[103] Greber, ., Webster, U. F., Weber, P., Helenius, J., \& , A. The role of the adenovirus protease on virus entry into cells. The EMBO J. (1996). Epub 1996/04/15., 15(8), 1766-77.

[104] Kalin, ., Amstutz, S., Gastaldelli, B., Wolfrum, M., Boucke, N., Havenga, K., et, M., \& al, . Macropinocytotic uptake and infection of human epithelial cells with species B2 adenovirus type (35). J Virol. 2010; . Epub 2010/03/20., 84(10), 5336-50.

[105] Willis, ., Goorha, D. B., Granoff, R., \& , A. Nongenetic reactivation of frog virus (3). DNA. Virology. 1979; . Epub 1979/10/30., 98(2), 476-9.

[106] Chitnis NS, D'Costa SM, Paul ER, Bilimoria SL. Modulation of iridovirus-induced apoptosis by endocytosis, early expression, JNK, and apical caspase. Virology. (2008). Epub 2007/10/19., 370(2), 333-42. 
32 Endocytosis 